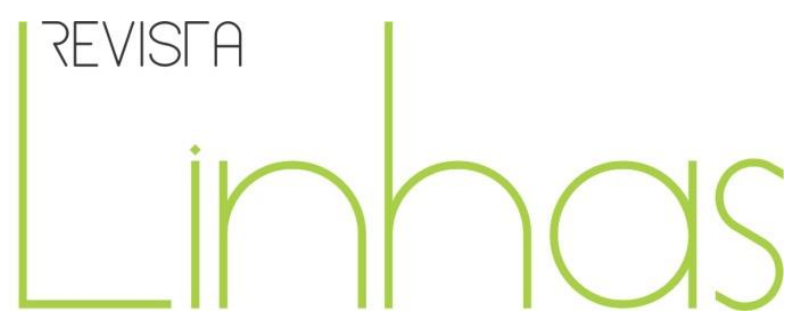

\title{
Geometria e Desenho numa perspectiva histórica: um estado da arte
}

\section{Resumo}

O objetivo deste artigo é apresentar um "estado da arte" das pesquisas em História da Educação Matemática que tratam especificamente sobre geometria e desenho no ensino primário. Para tanto, norteou-se pelas seguintes questões: Como e onde se situa, na atualidade, o quadro de pesquisas envolvendo geometria e desenho no ensino primário? Quais abordagens ou conhecimentos são produzidos por essas pesquisas? Considerando o período de 2000 a 2014, fez-se um levantamento de estudos que tratam do tema em questão junto ao banco de teses e de dissertações da Coordenação de Aperfeiçoamento de Pessoal de Nível Superior (CAPES), à Biblioteca Digital Brasileira de Teses e Dissertações (BDTD), a 12 sítios de Programas de Pós-Graduação e a 20 revistas nacionais na área da Educação Matemática, História da Educação e Educação. A partir dos dados encontrados, procuramos notificar a quantidade de pesquisas desenvolvidas, o local de produção e os sujeitos envolvidos. Por fim, percebemos que a pesquisa em História da Educação Matemática, tomando como foco a geometria e o desenho no ensino primário, é motivada pela compreensão histórica dos saberes escolares atuais e está associada a referenciais teóricos da Educação e da História.

Palavras-chave: Ensino primário; História da educação matemática; Ensino de Matemática.
Thaline Thiesen Kuhn

Doutoranda em Educação

Científica e Tecnológica pela

Universidade Federal de Santa

Catarina - UFSC - Brasil

thali_thiesen@hotmail.com

\section{Cláudia Regina Flores}

Doutora em Educação pela

Universidade Federal de Santa

Catarina - UFSC - Brasil

claudia.flores@ufsc.br

\section{Joseane Pinto de Arruda}

Doutora em Educação Científica e

Tecnológica pela Universidade

Federal de Santa Catarina - UFSC

- Brasil

jarruda@ca.ufsc.br

\section{Para citar este artigo:}

ARRUDA, Joseane Pinto de; FLORES, Cláudia Regina; KUHN, Thaline Thiesen. Geometria e Desenho numa perspectiva histórica: um estado da arte. Revista Linhas. Florianópolis, v. 167 n. 33, p. 309-332, jan./abr. 2016. 


\title{
Geometry and Drawing in historical perspective: a state of the art
}

\begin{abstract}
The objective of this paper is present a "state of the art" of research in mathematics education history dealing specifically with geometry and drawing in primary school. For this, it is guided by the following questions: How and where they are located, at present, the research framework involving geometry and drawing in primary school? What approaches or knowledge are produced by these studies? From the years 2000 to 2014, we conducted a survey of studies, that deal with the subject in question, covering: the bases of the theses and dissertations of Higher Education Personnel Training Coordination (CAPES), the Brazilian Digital Library of Theses and Dissertations (BDTD), the ten sites of Graduate Programs and the 20 national magazines in the field of Mathematics Education, History of Education and Education. From the data collected, we seek to notify the amount of research carried out, the place of production and the subjects involved. Finally, we conclude that the researchers are motivated by Historical understanding of the current school knowledge and the theoretical frameworks of Education and History are the bases associated with the research in mathematical education history focusing on geometry and the drawing in primary school.
\end{abstract}

Keywords: Primary education; History of Mathematics education; Teaching of Mathematics. 
Este artigo tem como propósito apresentar um "estado da arte"1 a respeito de produções de pesquisas envolvendo geometria e desenho no ensino primário², articuladas à História da Educação Matemática. Isso porque se percebe um interesse atual de pesquisadores ligados à área da Educação Matemática em problematizar historicamente os saberes escolares atuais.

Conforme Ferreira (2002), as pesquisas denominadas "estado da arte" ou "estado do conhecimento" têm por desafio mapear e discutir a produção em um determinado campo de conhecimento. Para a autora, um "estado da arte" se constitui, basicamente, em dois momentos distintos. O primeiro permite apresentar um panorama da produção acadêmica buscando uma quantificação e identificação de dados bibliográficos, além de mapear determinada produção em tempo e local delimitado. O segundo permite inventariar a produção analisada, verificando tendências, escolhas metodológicas e teóricas. No caso, buscando dialogar com esses dois momentos distintos, acredita-se que tudo isso poderá ser verificado no que diz respeito à escrita e produção da História da Educação Matemática, mapeando e inventariando pesquisas com o foco nos estudos voltados para o ensino de geometria e do desenho na escola primária. Norteou-se, portanto, pelas seguintes questões: Como e onde se situa, na atualidade, o quadro de pesquisas envolvendo geometria e desenho no ensino primário? Quais abordagens ou conhecimentos são produzidos por essas pesquisas?

Pode-se justificar esse propósito de estudo pela motivação de nossa parte em conhecer as produções que tratam sobre o assunto em questão. O que não significa, no entanto, estabelecer uma categorização simplista dessas pesquisas e trabalhos, apontando destaques, fragilidades e certezas. Ao contrário, o que se quer aqui é dar a conhecer um esboço, mesmo que provisório e parcial, do que se tem realizado de pesquisa a respeito da geometria e do desenho no ensino primário de outros tempos.

\footnotetext{
${ }^{1}$ Vale destacar que se trata de um estado da arte dentro das pesquisas no campo da Educação Matemática, que lidam com a história, portanto, privilegiou-se os periódicos e trabalhos neste campo.

${ }^{2}$ Nomenclatura da época correspondente às quatro primeiras séries do Ensino Fundamental. Atualmente, com a inserção da política de nove anos ao Ensino Fundamental, tem-se a denominação de "anos iniciais do Ensino Fundamental”, em decorrência da Lei nº 11.274/2006.
} 
Pois, entende-se que a partir desse dar e estar a conhecer produzindo um estado da arte, algumas aberturas podem ser criadas para se pensar em novas perspectivas de pesquisas em História da Educação Matemática.

Vale dizer ainda que este estudo, de mapear e inventariar pesquisas sobre geometria e desenho, articula-se também ao desenvolvimento de uma pesquisa em nível de mestrado desenvolvida no Grupo de Estudos Contemporâneos e Educação Matemática (GECEM) ${ }^{3}$. Tal pesquisa ${ }^{4}$ toma como foco a geometria e o desenho no ensino primário, buscando compreender de que modo esses saberes foram sendo constituídos para a escola primária e que relações podem ser estabelecidas entre esses dois ensinos ou não, a partir de uma análise de documentos que circularam nos grupos escolares catarinenses. Vale dizer que as aproximações entre a geometria e o desenho estavam permeadas de discursos e enunciados que se fizeram presentes em uma determinada época, criando uma série de dispositivos que foram colocados em prática para o ensino desses saberes. Ou seja, as aproximações entre tais matérias se situavam muito além dos conteúdos e metodologias específicas, mas nas expectativas políticas, econômicas e científicas.

Assim, para este artigo, inicialmente, fez-se um levantamento de teses e dissertações junto ao banco de teses da Coordenação de Aperfeiçoamento de Pessoal de Nível Superior (CAPES), à Biblioteca Digital Brasileira de Teses e Dissertações (BDTD), a 12 sítios de Programas de Pós-Graduação e a 20 revistas nacionais na área da Educação Matemática (16), História da Educação (3) e Educação (1), considerando o período de 2000 a 2014. Na sequência, realiza-se um mapeamento observando a quantidade de pesquisas desenvolvidas, o local de produção e os sujeitos envolvidos. Em seguida, apresenta-se uma breve descrição dos trabalhos, notando suas tendências, seus referenciais teóricos e produção de conhecimento histórico. Por último, tecem-se algumas considerações em torno dessa análise das pesquisas, envolvendo o ensino da geometria e do desenho no ensino primário de outros tempos.

\footnotetext{
${ }^{3}$ Grupo de estudos sediado no Departamento de Metodologia de Ensino da Universidade Federal de Santa Catarina, sob a coordenação da professora Dra. Cláudia Regina Flores. Para maiores informações ver site: http://www.gecem.ufsc.br/index.htm

4 Trata-se de uma pesquisa de mestrado desenvolvida no Programa de Pós-Graduação em Educação Científica e Tecnológica da Universidade Federal de Santa Catarina, intitulada "Aproximações da Geometria e do Desenho nos Programas de Ensino dos Grupos Escolares Catarinenses", sob a orientação das professoras Dra. Cláudia Regina Flores e Dra. Joseane Pinto de Arruda.
} 


\section{Um panorama das pesquisas}

O panorama que aqui se pretende fazer das pesquisas pode ser compreendido com a possibilidade de se tornar uma leitura aberta, desmontável e suscetível de receber alterações, por entendê-lo situado e, assim, provisório. Trata-se de um panorama que não deseja apenas reproduzir o que foi feito, mas buscar possíveis conexões e desconexões entre as pesquisas sobre geometria e desenho no ensino primário. Nesse caso, ao realizar esse estudo, procura-se interagir com a produção acadêmica, buscando quantificar, identificar e relacionar ou não dados bibliográficos, ideias e objetos tomados para o desenvolvimento de uma pesquisa.

Para Ferreira (2002), por exemplo, fazer um panorama, ou mapear as pesquisas, significa construir uma narrativa histórica da produção. No caso, podemos levar em conta a implantação e amadurecimento de grupos de pesquisa e/ou programas de pósgraduação concentrados neste tipo de pesquisa, apontando os períodos em que as pesquisas cresceram, locais de produção e agentes envolvidos. Da mesma forma, tornase possível pensar nas lacunas, ou possíveis aberturas para outros estudos, ainda não sinalizados pelas pesquisas.

Nessa direção, com base nas questões norteadoras para a escrita deste artigo, selecionou-se o período que compreende os anos de 2000 a 2014. A escolha por esse período pode ser justificada em decorrência de que os estudos em História da Educação Matemática, com foco no ensino primário, se intensificaram a partir da primeira década do século $X X 1^{5}$. A base de dados foi construída com as palavras-chave: ensino primário, escola primária, grupos escolares, combinadas com as palavras geometria ou desenho.

Buscaram-se, então, títulos de dissertações, teses e artigos que apresentassem familiaridade com as palavras-chave citadas acima. Em seguida, também, realizou-se a leitura do resumo dos trabalhos levantados e, a partir daí, selecionou-se aqueles que se alinhavavam com o tema de estudo em questão. Embora o resumo dos trabalhos

\footnotetext{
${ }^{5}$ As pesquisas em História da Educação Matemática têm crescido muito nos últimos anos no Brasil, tendo em vista a consolidação de grupos de pesquisas como: Grupo de Pesquisa de História da Educação Matemática no Brasil - GHEMAT, História Filosofia e Educação Matemática - HIFEM, Grupo de História Oral e Educação - GHOEM, entre outros.
} 
apresentasse de maneira sucinta e objetiva o que se pretendia pesquisar, foi necessária a leitura na íntegra dos trabalhos.

A construção desse panorama foi realizada em dois momentos. No primeiro momento foi feito um levantamento de dissertações e teses no Banco de Teses da Coordenação de Aperfeiçoamento de Pessoal de Nível Superior (CAPES), na Biblioteca Digital Brasileira de Teses e Dissertações (BDTD), e nos sítios dos seguintes Programas de Pós-Graduação: Programa de Pós-Graduação em Educação Matemática da PUC - SP, Programa de Pós-Graduação em Educação da PUC - PR, Programa de Pós-Graduação em Educação da UFPR, Programa de Pós-Graduação em Educação Científica e Tecnológica da UFSC, Programa de Pós-Graduação em Educação da UNICAMP, Programa de PósGraduação em Educação da USP, Programa de Pós-Graduação em Educação da UFRN, Programa de Pós-Graduação em Educação da UFPE, Programa de Pós-Graduação em Educação da UFPB, Programa de Pós-Graduação em Educação da UFPA, Programa de Pós-Graduação Stricto Sensu em Educação Matemática da USS e Programa de PósGraduação em Educação e Saúde na Infância e na Adolescência da UNIFESP.

Para este primeiro momento, buscou-se por pesquisas de mestrado e doutorado que investigaram sobre a geometria e o desenho no ensino primário. Diante da constatação de que as pesquisas cuja temática aqui proposta eram reduzidas, houve a necessidade de ampliar o estudo. Ou seja, buscou-se também por artigos publicados em periódicos nacionais, articulados à História da Educação Matemática, que abordassem a geometria e o desenho no ensino primário.

O segundo momento foi realizado em periódicos nacionais qualificados pela CAPES, na área de Educação Matemática ${ }^{6}$ e História da Educação ${ }^{7}$. No caso, foram selecionadas as seguintes revistas na área da Educação Matemática: Boletim GEPEM, Revista Metáfora Educacional, Educação Matemática Pesquisa, Linhas Críticas, Zetetiké, Caminhos da Educação Matemática em Revista, Bolema, Perspectivas da Educação Matemática, RPEM, RBECT, REVEMAT, REMATEC, Ulbra, Em Teia, Alexandria e Revista Brasileira de Ensino de Ciências e Tecnologia. Na área da História da Educação as revistas

\footnotetext{
6 As revistas selecionadas na área da Educação Matemática foram escolhidas no site http://www.sbembrasil.org.br/.

${ }^{7}$ As revistas na área da História da Educação foram selecionadas no site http://www.sbhe.org.br/.
} 
selecionadas foram: Cadernos de História da Educação, História da Educação, Revista Brasileira de História da Educação. E, por fim, a revista Horizontes, na área da Educação.

Dessa forma, ao realizarmos um levantamento das pesquisas sobre a geometria e o desenho na escola primária, mapeamos a quantidade de pesquisas desenvolvidas, notificando o crescimento, o local de produção e os sujeitos. Foi contabilizado um total de treze trabalhos, sendo sete do "tipo" dissertação (D), nenhuma do "tipo" tese $(T)$ e seis do "tipo" artigo (A), como mostra o quadro 1.

Quadro 1 - Quantidade de trabalhos realizados por ano

\begin{tabular}{|c|c|c|c|c|}
\hline \multirow{2}{*}{ Ano } & \multicolumn{3}{|c|}{ Tipo } & \multirow{2}{*}{ Total } \\
\cline { 2 - 5 } & Dissertação & Tese & Artigo & 2 \\
\hline 2007 & 2 & 0 & 1 & 3 \\
\hline 2011 & 2 & 0 & 2 & 2 \\
\hline 2012 & 0 & 0 & 1 & 1 \\
\hline 2013 & 0 & 0 & 2 & 5 \\
\hline Total & 7 & 0 & 6 & 13 \\
\hline
\end{tabular}

Fonte: Elaborado pelas autoras.

Os números apresentados no quadro 1 mostram que a produção de pesquisas relacionadas ao ensino de geometria e de desenho no ensino primário ainda é recente e pequena; apenas 13 (treze) trabalhos de pesquisa foram encontrados. Outro dado, que podemos destacar, é que nos últimos sete anos (2007-2014), apenas 7 (sete) dissertações foram desenvolvidas e 6 (seis) artigos e que, ainda, nenhuma tese foi desenvolvida relacionada ao tema em questão. Podemos sinalizar também, a partir do quadro 1, a pouca variação de quantidade de trabalhos entre os anos, isto é, de 1 (um) a 3 (três) trabalhos por ano. É importante observar que a maioria dos trabalhos publicados foram dissertações, somando 7 (sete).

No quadro 2 são apresentados os trabalhos em ordem cronológica, relacionados ao local de produção, autores e às respectivas fontes de consultas, classificados pelos "tipos" de trabalhos. 
Quadro 2 - Local de produção e os autores

\begin{tabular}{|c|c|c|c|c|}
\hline Ano & Autor & Título & Fonte & “Tipo" \\
\hline 2007 & $\begin{array}{l}\text { Denise Medina de } \\
\text { Almeida França }\end{array}$ & $\begin{array}{l}\text { A produção oficial do } \\
\text { Movimento da } \\
\text { Matemática Moderna } \\
\text { para o ensino primário do } \\
\text { estado de São Paulo } \\
\text { (1960-1980) }\end{array}$ & $\begin{array}{l}\text { Programa de Pós- } \\
\text { Graduação em } \\
\text { Educação Matemática } \\
\text { - PUC/SP }\end{array}$ & $D$ \\
\hline 2007 & $\begin{array}{c}\text { Ricardo Soares de } \\
\text { Meneses }\end{array}$ & $\begin{array}{c}\text { Uma história da } \\
\text { geometria escolar no } \\
\text { Brasil: de disciplina a } \\
\text { conteúdo de ensino }\end{array}$ & $\begin{array}{c}\text { Programa de Pós- } \\
\text { Graduação em } \\
\text { Educação Matemática } \\
\text { - PUC/SP } \\
\end{array}$ & D \\
\hline 2011 & $\begin{array}{c}\text { Felipe Freitas de } \\
\text { Souza }\end{array}$ & $\begin{array}{l}\text { O desenho é a escrita da } \\
\text { Indústria: Ensino de } \\
\text { desenho e educação } \\
\text { profissional em Rui } \\
\text { Barbosa } \\
\end{array}$ & $\begin{array}{c}\text { Centro Federal de } \\
\text { Educação Tecnológica } \\
\text { de Minas Gerais }\end{array}$ & D \\
\hline 2011 & $\begin{array}{c}\text { Maria Laura } \\
\text { Magalhães Gomes }\end{array}$ & $\begin{array}{c}\text { Lições de coisas: } \\
\text { apontamentos acerca da } \\
\text { geometria no manual de } \\
\text { Norman Allison Calkins } \\
\text { (Brasil, final do século XIX } \\
\text { e início do século XX) } \\
\end{array}$ & $\begin{array}{l}\text { Revista Brasileira de } \\
\text { História da Educação }\end{array}$ & A \\
\hline 2011 & $\begin{array}{c}\text { Manoel Francisco } \\
\text { Barreiros }\end{array}$ & $\begin{array}{c}\text { O ensino de geometria } \\
\text { nos Grupos Escolares do } \\
\text { estado de São Paulo } \\
(1890 \text { a 1930) }\end{array}$ & $\begin{array}{c}\text { Programa de Pós- } \\
\text { Graduação em } \\
\text { Educação Matemática } \\
\text { - UNIBAN } \\
\end{array}$ & D \\
\hline 2012 & $\begin{array}{c}\text { Maria Célia Leme da } \\
\text { Silva, Wagner } \\
\text { Rodrigues Valente }\end{array}$ & $\begin{array}{l}\text { A geometria dos grupos } \\
\text { escolares: matemática e } \\
\text { pedagogia na produção } \\
\text { de um saber escolar }\end{array}$ & $\begin{array}{c}\text { Cadernos de História } \\
\text { da Educação }\end{array}$ & A \\
\hline 2012 & $\begin{array}{c}\text { Wagner Rodrigues } \\
\text { Valente }\end{array}$ & $\begin{array}{l}\text { Tempos de Império: a } \\
\text { trajetória da geometria } \\
\text { como um sabe escolar } \\
\text { para o curso primário }\end{array}$ & $\begin{array}{l}\text { Revista Brasileira de } \\
\text { História da Educação }\end{array}$ & A \\
\hline 2013 & $\begin{array}{c}\text { Maria Célia Leme da } \\
\text { Silva, Wagner } \\
\text { Rodrigues Valente }\end{array}$ & $\begin{array}{c}\text { Programas de geometria } \\
\text { no ensino primário } \\
\text { paulista: do império à } \\
\text { primeira república } \\
\end{array}$ & Horizontes & A \\
\hline 2014 & $\begin{array}{c}\text { Ivanete Batista dos } \\
\text { Santos }\end{array}$ & $\begin{array}{c}\text { Os saberes elementares } \\
\text { matemáticos nos grupos } \\
\text { escolares: um primeiro } \\
\text { balanço (Sergipe, 1911- } \\
\text { 1930) }\end{array}$ & $\begin{array}{c}\text { Caminhos da Educação } \\
\text { Matemática }\end{array}$ & $A$ \\
\hline
\end{tabular}




\begin{tabular}{|c|c|c|c|c|}
\hline 2014 & $\begin{array}{c}\text { Maria Célia Leme da } \\
\text { Silva }\end{array}$ & $\begin{array}{c}\text { Desenho e Geometria na } \\
\text { escola primária; um } \\
\text { casamento duradouro } \\
\text { que termina com } \\
\text { separação litigiosa }\end{array}$ & $\begin{array}{l}\text { Revista História da } \\
\text { Educação }\end{array}$ & A \\
\hline 2014 & $\begin{array}{l}\text { Piersandra Simão } \\
\text { dos Santos }\end{array}$ & $\begin{array}{c}\text { A escolarização da } \\
\text { matemática no grupo } \\
\text { escolar Lauro Muller } \\
(1950-1970) \\
\end{array}$ & $\begin{array}{l}\text { Programa de Pós- } \\
\text { Graduação em } \\
\text { Educação Científica e } \\
\text { Tecnológica - UFSC } \\
\end{array}$ & $D$ \\
\hline 2014 & $\begin{array}{l}\text { Jorge Alexandre dos } \\
\text { Santos Gaspar }\end{array}$ & $\begin{array}{l}\text { O desenho escolar no Rio } \\
\text { de Janeiro: uma história } \\
\text { de } 1890 \text { a } 1964\end{array}$ & $\begin{array}{l}\text { Programa de Pós- } \\
\text { Graduação Stricto } \\
\text { Sensu em Educação } \\
\text { Matemática - USS }\end{array}$ & D \\
\hline 2014 & $\begin{array}{c}\text { Claudia Regina Boen } \\
\text { Frizzarini }\end{array}$ & $\begin{array}{c}\text { Do ensino intuitivo para a } \\
\text { escola ativa: os saberes } \\
\text { geométricos nos } \\
\text { programas do curso } \\
\text { primário paulista, 1890- } \\
1950\end{array}$ & $\begin{array}{l}\text { Programa de Pós- } \\
\text { Graduação em } \\
\text { Educação e Saúde na } \\
\text { Infância e na } \\
\text { Adolescência - } \\
\text { UNIFESP }\end{array}$ & D \\
\hline
\end{tabular}

Fonte: Elaborado pelas autoras.

A partir dos dados do quadro 2, pode-se observar que, dos 12 programas de pósgraduação em que se realizou a busca, apenas em 7 (sete) foram encontrados trabalhos que tratassem sobre a geometria e o desenho no ensino primário, isto é, 2 (dois) trabalhos na PUC-SP, 1 (um) na UNIBAN, 1 (um) na UFSC, 1 (um) no CEFET-MG, 1 (um) na USS e 1 (um) na UNIFESP. E, ainda, dessas 7 (sete) dissertações, apenas 2 (duas) tratam sobre o desenho, as outras 5 (cinco) tratam da geometria.

Com relação às três revistas selecionadas na área da História da Educação, as mesmas tiveram publicações sobre a temática abordada, sendo que a revista História da Educação e a Revista Brasileira de História da Educação tiveram duas publicações e, as revistas Cadernos de História da Educação, apenas uma publicação. A revista Horizontes, na área da Educação, também teve apenas uma publicação.

É interessante notar, também, que das revistas na área da Educação Matemática levantadas para a pesquisa, apenas uma teve publicação do tema em questão; trata-se da Revista Caminhos da Educação Matemática. Vale dizer que as publicações referentes às outras revistas na área da Educação Matemática estavam voltadas para o ensino de aritmética e matemática no ensino primário, ou, se referiam ao ensino primário em geral, 
sem foco na geometria e no desenho, ou seja, a discussão no ensino da matemática de outros tempos, centrava-se na aritmética e métodos de ensino.

Convém dizer, ainda, que do levantamento realizado por meio das palavras-chave foram excluídos 6 (seis) trabalhos, a saber: 3 (três) teses que indicavam apenas a presença destas disciplinas no currículo, sem trazer maiores informações como, por exemplo, as teses de Joseane Pinto de Arruda (2011), Dilma Maria Andrade de Oliveira (2004) e José Claudio Sooma Silva (2009); 2 (duas) dissertações, de Olinda Pereira (2012), que teve como foco de análise a geometria no ensino primário, mas no Timor Leste, e a dissertação de Rosilene Beatriz Machado (2012), que trata da história da disciplina de desenho, no período de 1960 a 2000, questionando os motivos que levaram a extinção desta disciplina do currículo. E ainda, o artigo de Renauld D’Enfert (2007) que aborda especificamente o ensino de desenho, nesse caso, o ensino de Desenho Linear na escola primária francesa. Por desenho linear entende-se que ele "engloba, sobretudo um método de ensino elementar de Desenho, isto é, um conjunto de procedimentos didáticos que fornece os "elementos"” para subsidiar o ensino de Desenho em espaço escolar (D’ENFERT, 2007, p. 43).

Outro dado que se mostra relevante, por meio dos quadros (1 e 2), é a ausência observada de trabalhos realizados sobre a geometria e o desenho entre os anos de 2008 a 2010. O que leva a interrogar sobre um possível desinteresse de pesquisa a respeito desses saberes, possivelmente, priorizando outros estudos como a aritmética, ou ainda sobre metodologias no ensino primário.

\section{Compreendendo as pesquisas}

A partir desse panorama inicial, que identifica algumas produções acerca do tema de estudo em questão, buscou-se dialogar com esses dados, ou seja, compreender as pesquisas que foram levantadas procurando possíveis abordagens e conhecimentos produzidos sobre o tema para, assim, ampliar a discussão dos trabalhos levantados, o que pode se constituir numa perspectiva de inventariar. Nessa direção, entende-se conforme Ferreira (2002, p. 265), que ao fazer um inventário, o pesquisador "deve buscar 
responder, além das perguntas "quando", “onde" e "quem" produz pesquisas num determinado período e lugar, àquelas questões que se referem a "o quê" e "o como" dos trabalhos".

Assim, o inventário a seguir apresenta uma breve descrição dos trabalhos mapeados, buscando destacar aspectos relacionados aos objetivos, metodologias, resultados e considerações feitas pelos autores. Vale destacar que para inventariar foi necessário não apenas a leitura do resumo, mas a leitura na íntegra das pesquisas elencadas. Da mesma forma, com a intenção de dialogar melhor com tais pesquisas, apresentando-as, optou-se por fazer o inventário descrevendo primeiramente as dissertações e, posteriormente, os artigos.

\section{Das dissertações}

A dissertação de Denise Medina de Almeida França (2007), “A produção oficial do Movimento da Matemática Moderna para o Ensino Primário no Estado de São Paulo", apresenta um estudo sobre as alterações curriculares da Matemática no Ensino Primário paulista, no período de 1960 a 1980, buscando identificar os processos de apropriação desse movimento pela Secretaria de Educação do Estado de São Paulo. A autora fez uso da abordagem da História Cultural e utilizou como fontes o Programa da Escola Primária do Estado de São Paulo, de 1969; os Guias Curriculares para o ensino de $1^{\circ}$ grau, de 1975;

Subsídios para a implementação dos Guias Curriculares de Matemática - Álgebra e Geometria, de 1981; Lei de Diretrizes e Bases, de 1961 e 1971; e Entrevistas com protagonistas do Movimento da Matemática Moderna. França (2007) concluiu que, no período estudado, os documentos oficiais foram utilizados como estratégia produzida pelo Estado, visando à reformulação curricular e divulgação, a fim de implementar as novas diretrizes para o ensino de Matemática na escola primária paulista. Comprovou, também, a oficialização do ideário do $M M M$ no ensino primário por meio desses documentos, relacionando-os com as transformações na estrutura do currículo da matemática e as normativas impostas pelas Leis de Diretrizes e Bases, de 1961 e 1971. Em seu estudo, afirmou que o ensino de matemática era formado pelos conteúdos de aritmética e geometria. Embora o foco não fosse o ensino da geometria, a autora 
apresentou pequenos indícios de como este era constituído no ensino primário paulista. Ou seja, a geometria era tratada axiomaticamente, mediante um caráter abstrato e conforme o estudo de propriedades, objetivando o reconhecimento e estudo das relações. Ao fazer uma análise do guia curricular de geometria, destacou que esta era dividida em figuras geométricas, transformações geométricas e medidas, e que para o ensino das séries iniciais eram priorizadas noções topológicas, projetivas, de paralelismo e semelhança, euclidianas, além de comprimento e área. A geometria era abordada, segundo a autora, dentro de uma visão estruturalista da matemática, com base na linguagem da teoria dos conjuntos e no conceito de funções e relações, conforme recomendava o ideário do $M M M$.

Em sua dissertação, "Uma história da geometria escolar no Brasil: de disciplina a conteúdo de ensino", Ricardo Soares de Meneses (2007) realizou um estudo histórico sobre o ensino de geometria no Brasil, tendo como fonte de pesquisa os livros didáticos. No estudo, amparando-se nas reflexões da História Cultural, o autor descreve a trajetória do ensino de Geometria no Brasil, do início do século XVII até as primeiras décadas do século XX. Em primeiro lugar, abordou os ideais do Movimento Internacional (IMUK), o qual propunha que a Álgebra, a Aritmética e a Geometria se fundissem em uma única disciplina denominada Matemática. Depois, o papel de Euclides Roxo, que aderiu ao movimento liderado por Felix Klein, implementando essas disciplinas no sistema educacional brasileiro e, por último, as propostas para o ensino de matemática, advindas da reforma Francisco Campos que utilizava como fontes os livros didáticos da época. Meneses (2007) apontou duas etapas fundamentais desse ensino: a primeira, em que a Geometria se torna, no ensino secundário brasileiro, uma disciplina autônoma devido à exigência desse conteúdo para o ingresso nos cursos superiores, e a segunda, em que a Geometria passa a ser conteúdo de uma disciplina escolar denominada Matemática na Reforma Francisco Campos.

Já Felipe Freitas de Souza (2011), em sua dissertação “O desenho é a escrita da indústria: ensino de desenho e educação profissional em Rui Barbosa" realizou um estudo sobre o ensino de desenho e suas relações com as proposições de educação profissional, a partir das obras de Rui Barbosa, quais sejam, a Reforma do ensino secundário e superior; a Reforma do ensino primário e várias instituições complementares da instrução pública; e o 
discurso intitulado $\mathrm{O}$ desenho e a arte industrial. $\mathrm{O}$ autor utilizou-se dos estudos advindos da História Cultural, por meio do conceito de tradução cultural, para elaborar algumas influências propagadas por Rui Barbosa a respeito do ensino de desenho. Souza (2011) destacou que, em suas obras, Rui Barbosa expunha a necessidade de se incluir essa disciplina na escola primária, por favorecer a preparação do trabalhador.

A dissertação de Manoel Francisco Barreiros (2011), intitulada "O Ensino de Geometria nos Grupos Escolares do Estado de São Paulo (1890 a 1930)", investigou o processo de ensino de geometria no curso primário dos Grupos Escolares do Estado de São Paulo no período de 1890 a 1930, durante a Primeira República. A metodologia utilizada na pesquisa baseou-se nos pressupostos da História Cultural, utilizando-se de fontes como a Revista de Ensino da Associação Beneficente do Professorado Público de São Paulo e as obras didáticas Desenho linear ou elementos de geometria prática popular, de autoria de Abílio César Borges, publicada em 1822, e Noções de geometria prática, de autoria de Olavo Freire, de 1894, $1^{\mathrm{a}}$ edição. Além disso, também foram analisados os exames finais de matemática dos anos de 1896 e 1900. Barreiros (2011) destacou que os livros analisados eram dirigidos antes aos professores e depois aos alunos. Da mesma forma, ao analisar as questões das provas e dos exames e as respostas apresentadas pelos alunos, o autor verificou quais eram as expectativas de aprendizagem de geometria nos grupos escolares. Com isso, observou que, dentre as expectativas a respeito do que os alunos deveriam saber sobre geometria, estavam à memorização de definições, propriedades e construções geométricas, contrariando as orientações metodológicas das reformas educacionais que propunham um ensino mais intuitivo e menos enciclopédico, voltado para a prática.

A dissertação de Piersandra Simão dos Santos (2014b), "A Escolarização da Matemática no Grupo Escolar Lauro Müller (1950 - 1970)", por sua vez, se propôs a compreender como se deu a escolarização da matemática, representada pelos conteúdos de aritmética e de geometria, nos primeiros anos de escolaridade no Grupo Escolar Lauro Müller (GELM), entre as décadas de 1950 e 1970. A pesquisa foi realizada sobre a legislação oficial da época, como as leis, decretos e normas que colocaram em prática os grupos escolares de Santa Catarina, além de entrevistas com ex-alunos e uma professora dessa antiga instituição escolar. Santos (2014b) concluiu que, por meio da legislação 
oficial e das memórias dos entrevistados, a escolarização da matemática no GELM foi marcada por enunciados e discursos, sendo que esses moldavam, criavam e prescreviam dispositivos para a matemática, tornando-se práticas nas salas de aula. Com relação ao ensino de geometria, a autora destaca que os conteúdos para esse ensino apareciam em menos quantidade se comparados com a aritmética. O ensino da geometria era explorado por meio do estudo de sólidos geométricos, triângulos, quadriláteros e circunferências, incluindo também a resolução de problemas envolvendo os conhecimentos geométricos. Ela destacou também o uso de materiais manipuláveis para o ensino da geometria, tais como régua, malha quadriculada e compasso.

Jorge Alexandre dos Santos Gaspar (2014), em sua dissertação intitulada "O desenho escolar no Rio de Janeiro: uma história de 1890 a 1964" traçou historicamente o percurso da disciplina escolar Desenho, em especial, o Desenho Geométrico, no período compreendido entre os anos iniciais da República, em 1890, até o início do movimento civil-militar, de 1964. A base teórico-metodológica utilizada na pesquisa foi a história das disciplinas escolares e a cultura escolar. Gaspar (2014) utilizou, como fonte de pesquisa, os autores e as obras mais importantes para o ensino de Desenho, sobretudo o Desenho Geométrico, utilizando-se do acervo da Biblioteca Nacional, no Rio de Janeiro. Além disso, também foram utilizadas as legislações e as propostas curriculares de dois estabelecimentos de ensino, o Colégio Militar do Rio de Janeiro e o Colégio Pedro II, a fim de saber até que ponto as leis foram influenciadas pelos livros publicados e pelos programas elaborados pelos colégios durante o período em estudo, ou se influenciaram na confecção de novos manuais didáticos. O autor destaca que o Desenho teve seu conteúdo dividido em: Desenho a mão livre, Desenho Linear, Desenho Geométrico Linear e Perspectiva. Nas obras consultadas é possível perceber uma linearidade dos conteúdos, que começava com desenho a mão livre, mediante elementos básicos da geometria, sem o uso de instrumentos. Em seguida, o conteúdo abordado trabalhava as construções mais simples, envolvendo linhas e ângulos, até construções mais complexas, como concordâncias de curvas e elementos cônicos, denominados como desenho geométrico linear ou desenho com auxílio de instrumentos. Por fim, a terceira parte das obras dedicava-se ao desenho decorativo, em que eram utilizadas as construções geométricas 
para o traçado de malhas geométricas lineares e circulares, bem como elementos ornamentais.

Já a dissertação de Claudia Regina Boen Frizzarini (2014), “Do ensino intuitivo para a escola ativa: os saberes geométricos nos programas do curso primário paulista, 18901950", analisou as orientações oficiais de ensino do curso primário paulista no período de 1890 a 1950, com os saberes geométricos: Formas, Geometria, Desenho, Modelagem, Aritmética e Trabalhos Manuais. O referencial teórico-metodológico mobilizado foi a História Cultural, utilizando como fonte as orientações oficiais de ensino, programas de ensino paulistas e os manuais didáticos Primeiras Lições de Coisas e Manual do ensino primário. A autora destaca que a análise das fontes revelou as grandes marcas dos movimentos educacionais, intuitivo e escolanovista presentes nas matérias geométricas, além de apontar novas metodologias, conteúdos e matérias que se inseriam ao longo dos programas e que determinariam como os saberes geométricos eram apresentados ao ensino primário paulista. Da mesma forma, os manuais didáticos analisados têm grande parte de suas metodologias e prescrições apropriadas aos programas de ensino primário de São Paulo.

A partir do inventário, fazendo uma análise das 7 (sete) dissertações, pode-se destacar que as de autoria de França (2007), de Meneses (2007), de Souza (2011), de Barreiros (2011), de Gaspar (2014) e de Frizzarini (2014) fizeram uso da abordagem da História Cultural, utilizando conceitos como representação, apropriação, estratégia, história das disciplinas escolares, cultura escolar e tradução cultural. Santos (2014b), por sua vez, apoiou-se na perspectiva da operação historiográfica de Certeau e trouxe à luz alguns conceitos foucaultianos, tais como discurso, enunciado e dispositivo. É possível destacar também que apenas 2 (duas) dissertações, a de Meneses (2007) e de Barreiros (2011), tiveram como foco principal o ensino de geometria. Já Santos (2014b) e França (2007) tiveram como foco o ensino da matemática, representado pelos saberes aritmética e geometria. O trabalho de autoria de Frizzarini (2014) analisou as orientações oficiais de ensino do curso primário paulista com os saberes geométricos: Formas, Geometria, Desenho, Modelagem, Aritmética e Trabalhos Manuais. E, por fim, pode-se ainda citar que a pesquisa de Souza (2011) abordou o ensino de desenho em suas relações com as proposições de educação profissional, por meio das obras de Rui Barbosa, 
enquanto que a de Gaspar (2014) traçou historicamente o percurso da disciplina escolar Desenho, em especial, o Desenho Geométrico, no Rio de Janeiro.

Vale dizer que nenhuma dissertação teve como foco específico relacionar o ensino de geometria e do desenho no ensino primário, no sentido de trazer aproximações ou afastamentos entre esses dois saberes escolares.

\section{Dos artigos}

Em seu artigo, “Lições de coisas: apontamentos acerca da geometria no manual de Norman Allison Calkins (Brasil, final do século XIX e início do XX)", Maria Laura Magalhães Gomes (2011) buscou analisar o livro Primeiras lições de coisas, de Norman Allison Calkins, a respeito dos conhecimentos matemáticos, especialmente as lições de geometria. Tal obra, segundo analisou Gomes (2011), propõe o método intuitivo como um processo geral de ensino de todos os conteúdos a serem trabalhados com as crianças da escola primária. A autora destacou cinco aspectos da abordagem metodológica adotada: a presença da geometria plana antes da espacial; os diversos materiais essenciais ao ensino da geometria; a associação do desenho ao ensino; a sequenciação dos conteúdos geométricos; e a ligação ao prazer e à curiosidade da criança.

No artigo “A Geometria dos Grupos Escolares: Matemática e Pedagogia na Produção de um Saber Escolar", os autores, Maria Célia Leme da Silva e Wagner Rodrigues Valente (2012) apresentaram um estudo histórico sobre a constituição de uma geometria para ser ensinada no curso primário. O objetivo era analisar a trajetória da matéria geometria nos grupos escolares paulistas, desde a sua criação em 1893 até meados do século XX, e discutir as relações estabelecidas entre Matemática e Pedagogia para a produção de um saber escolar. Os autores concluíram que a apropriação de movimentos pedagógicos ocorre de modo diferenciado ao longo do recorte temporal pesquisado, possibilitando ou não a elaboração de novos saberes escolares, de modo que a recepção de novas pedagogias resulta em diferentes formas de apropriação, de acordo com cada saber presente no cotidiano escolar. Os conteúdos de geometria eram explorados por meio de métodos emergentes nesses movimentos pedagógicos; Silva e 
Valente (2012) analisam a transformação da geometria na passagem do ensino intuitivo para o ensino ativo. A geometria escolar voltava a atenção para as lições de coisas, para o método intuitivo, sendo que, de modo intuitivo revelaria seu caráter prático. Com a chegada da Escola Nova, foi possível unir a geometria prática com as propostas escolanovistas, de um ensino de caráter experimental. A geometria intuitiva servia como modus operandi das orientações para as práticas pedagógicas escolanovistas.

O artigo de Wagner Rodrigues Valente (2012), intitulado "Tempos de Império: a trajetória da geometria como um saber escolar para o curso primário", analisou a trajetória inicial de constituição da geometria como uma das matérias de ensino do curso primário brasileiro, com base na apropriação das propostas de Condorcet, emergentes nas discussões do Congresso Nacional brasileiro e na elaboração de uma geometria prática para ensino nos anos iniciais escolares. As fontes utilizadas para a pesquisa foram os livros didáticos, as discussões legislativas, as leis e os decretos elaborados para orientar o ensino desse conteúdo escolar. O autor assinalou que os resultados do estudo realizado apontaram para a sedimentação do desenho linear como uma geometria para o curso primário.

No artigo "Programas de geometria no ensino primário paulista: do império à primeira república”, os autores, Silva e Valente (2013) investigaram o ensino de geometria no curso primário do final do século XIX ao início do século XX. As fontes utilizadas para a análise consistiram em normas legislativas da educação e programas propostos para a matéria de geometria, no Estado de São Paulo. Silva e Valente (2013), apontam que a Reforma da Instrução Pública de 1892 consolidou a entrada da geometria como matéria para compor o programa do ensino primário, com a denominação de Geometria prática.

Ivanete Batista dos Santos (2014a), em seu artigo “Os saberes elementares matemáticos nos grupos escolares: um primeiro balanço (Sergipe, 1911 - 1930)", apresentou um primeiro balanço sobre os saberes elementares matemáticos (aritmética, geometria e desenho), abordados em grupos escolares em Sergipe, utilizando como fontes os Decretos, os Regulamentos da Instrução Primária e os Programas de Ensino. A autora destacou que os programas de 1912, 1915, 1916 e 1917 trazem poucas alterações em relação ao ensino de aritmética e que não há separação entre os ensinos de geometria e de desenho. No entanto, a autora sinalizou que o programa de 1924 trazia, em sua 
proposta, os saberes geométricos relacionados aos saberes aritméticos. Santos (2014a) verificou que no período pesquisado, 1911-1930, recomendava-se o método intuitivo para o ensino dos saberes matemáticos elementares, sem que o aluno precisasse ter contato com conteúdos considerados abstratos ou complexos, e sem antes passar por conceitos mais simples.

Em seu artigo intitulado, "Desenho e Geometria na Escola Primária: Um Casamento Duradouro que Termina com Separação Litigiosa", Maria Célia Leme da Silva (2014) analisou a trajetória do desenho e da geometria na escola de primeiras letras, problematizando os momentos de proximidade e de afastamento entre essas duas disciplinas, tomando como fonte de pesquisa as legislações e as revistas pedagógicas de grande circulação no período analisado. A autora conclui afirmando que, inicialmente, houve uma relação de dependência entre a geometria e o desenho, ou seja, as figuras geométricas assumiam o papel de condutoras para a metodologia do ensino de desenho. No entanto, na virada entre os séculos XIX e XX, a relação de dependência entre geometria e desenho se rompe com a separação entre conteúdo e método de ensino, momento em que cada matéria passou a ter objetivos diferentes.

Ao analisar os artigos levantados, foi possível observar que os de autoria de Gomes (2011), Silva e Valente (2012, 2013), e Valente (2012) realizaram um estudo sobre a geometria no ensino primário, utilizando como fontes livros, decretos e programas de ensino, enquanto que nos três últimos, os autores fizeram um estudo sobre a trajetória da geometria no curso primário. Uma leitura dos artigos de Gomes (2011), Silva e Valente (2012; 2013), e Valente (2012) permite saber que, para o ensino primário, a geometria era apresentada com a denominação de geometria prática, na qual se relacionavam os conceitos geométricos com objetos e ferramentas da vida prática. É possível agregar também que tal geometria associada como prática se dava a partir do uso e da manipulação de instrumentos como, por exemplo, o compasso e a régua a fim de realizar construções geométricas.

Os artigos de autoria de Santos (2014a) e Silva (2014), que versam sobre a geometria e o desenho no ensino primário, destacaram que, em certo momento, houve uma ligação entre o ensino desses dois saberes e que, posteriormente, houve a separação entre conteúdo e método de ensino. Santos (2014a), por exemplo, destacou 
que no Programa de 1912 não houve uma separação entre os saberes de geometria e os saberes de desenho. Já no programa de 1924, a mesma autora verificou que os saberes geométricos passaram a ser explorados com o ensino de aritmética. Por sua vez, Silva (2014) verificou que a geometria e o desenho tinham uma proximidade no que diz respeito aos conteúdos, ou seja, o desenho era introduzido pelas figuras geométricas e a geometria representada pelo desenho, uma vez que se tratava de saberes que seguiam trajetórias similares. No entanto, a autora afirma que, com a reforma de $1905^{8}$, houve alterações para as duas matérias nos programas do ensino primário, desaparecendo os conceitos geométricos da matéria de desenho e ficando restritos à matéria de geometria.

\section{Algumas considerações}

A realização deste "estado da arte" possibilitou um esboço geral acerca da produção de pesquisas, envolvendo geometria e desenho no ensino primário, no período de 2000 a 2014, na área da História da Educação Matemática. Nessa direção, algumas considerações podem ser realizadas.

Uma dessas considerações é que tais produções ou pesquisas, cuja temática aqui é proposta, ainda são bastante reduzidas, talvez porque sejam recentes. Embora em número reduzido, o interesse em realizar tais pesquisas parece se fortalecer nos últimos quatro anos, mediante o impulso de determinados grupos de pesquisas preocupados com a constituição histórica dos saberes elementares ao ensino da matemática, o que permite interrogar se o tema geometria e desenho no ensino primário não está emergindo como mais um tema relevante, sendo alimentado atualmente por propostas e estudos de grupos de pesquisas, associados especificamente à História da Educação Matemática ${ }^{9}$, ou ainda como um tema que até então tinha sido desconsiderado no cenário de pesquisa em História da Educação Matemática.

\footnotetext{
${ }^{8}$ Decreto n. 1281, de 24 de abril de 1905 (SILVA, 2014).

${ }^{9}$ Apenas para ilustrar, ao realizar um levantamento bibliográfico de dissertações e teses da área da Educação Matemática no Círculo de Estudo, Memória e Pesquisa em Educação Matemática (CEMPEM), da UNICAMP, apontou quase a inexistência de pesquisas históricas sobre a educação matemática nas quatro primeiras séries da escolaridade.
} 
Outra consideração diz respeito aos artigos aqui elencados, a maioria deles (4) foram publicados em revistas ou periódicos indexados da Educação e da História da Educação. Tal fato permite destacar certa relação e articulação de discursos construídos por pesquisadores da História da Educação Matemática e da História da Educação. A articulação entre esses dois campos, por exemplo, é discutida por Valente (2005). O referido autor compreende a história da matemática escolar como uma especialização da História da Educação, argumentando que a matemática escolar se insere em um contexto sociocultural e econômico, não desvinculado das problematizações que envolvem os objetos que pertencem ao ensino e à escola.

Ainda vale considerar, conforme análise, a quase unanimidade da abordagem teórica e metodológica da História Cultural nas pesquisas aqui elencadas. Tal fato parece derivar como uma tendência presente também junto aos pesquisadores da História da Educação $^{10}$. O que, possivelmente, poder-se-ia interrogar, de um lado, se essa vertente não estaria nos discursos dos pesquisadores em História da Educação Matemática para demarcar a relação com a História da Educação. Do outro lado, poder-se-ia interrogar se tais discursos não criam um modo identitário, seguindo um padrão de aceitação de se fazer pesquisa, a partir de mesmos referenciais.

De outra maneira, outra consideração é que se percebeu um enfoque maior das pesquisas ou produções levantadas, de modo geral, para uma trajetória da geometria como mais um saber escolar no ensino primário. Essas pesquisas associaram a presença e alterações desse saber às mudanças curriculares sofridas ao longo do tempo, devido a reformas educacionais. Nesse sentido, o destaque das pesquisas foi a ideia de uma geometria prática, que pode ser interpretada na medida em que os conceitos estudados são relacionados com objetos da vida prática. E, ainda, o emprego do método intuitivo como principal orientação metodológica nos programas e obras, bem como o uso de materiais manipuláveis e instrumentos para esse ensino.

\footnotetext{
${ }^{10}$ Consultar, por exemplo, VIDAL, Diana Gonçalves. Culturas Escolares: estudo sobre práticas de leitura e escrita na escola pública primária. Campinas - SP: AA, 2005; FARIA FILHO, Luciano Mendes de. Escolarização, culturas e práticas escolares no Brasil: elementos teórico-metodológicos de um programa de pesquisa. In: LOPES, Aline et al. Disciplinas e integração curricular: histórias e políticas, RJ: DP\&A, p.13-36, 2002; CARVALHO, Marta Maria Chaga de. Por uma história cultural dos saberes pedagógicos. In: SOUSA, Cyntia Pereira de; CATANI, Denice Barbara (orgs.). Práticas educativas, culturas escolares, profissão docente. SP: São Paulo: Escrituras, p. 31-41, 1998.
} 
No entanto, a respeito do desenho como uma disciplina ${ }^{11}$, muito pouco pode ser observado nas pesquisas. Da mesma forma que, outra consideração diz respeito ao pouco conhecimento produzido sobre o envolvimento do ensino da geometria e do desenho como saberes possivelmente complementares ou não, nos programas e nas escolas primárias. O que daria abertura, entre outros temas, para a produção de pesquisas nessa direção, qual seja, a de ampliar estudos particularmente sobre o desenho e a geometria como disciplinas articuladas ou não, discutindo possíveis aproximações entre tais ensinos na escola primária de outros tempos, como é o caso da pesquisa de Kuhn (2015).

Assim, embora a proposta neste artigo tenha sido a de produzir um estado da arte para "conhecer" as produções realizadas sobre o tema geometria e desenho no ensino/escola primária, a partir de um panorama e inventário, entende-se que muito ainda há de ser problematizado neste "conhecido", para além dessas ainda poucas pesquisas. Ou seja, muito mais que trazer dados, trabalhá-los e discuti-los sobre tais pesquisas, também se poderia aqui tratar das dificuldades muitas vezes enfrentadas por pesquisadores que se lançam na História da Educação Matemática. Pois, ir ao encontro das fontes para a escrita de um ou mais saberes matemáticos envolve conviver com descartes de documentos, pessoas que não estão mais entre nós e, ainda, indagações pragmáticas de colegas como, por exemplo, perguntar o porquê pesquisar sobre o ensino de geometria e de desenho de tempos idos.

Finalizando, portanto, acredita-se que este artigo além de ter situado, mesmo que provisoriamente, pesquisas envolvendo a geometria e o desenho na escola primária do passado, pode fornecer também alguns elementos de discussão como, por exemplo, criando algumas aberturas para pensar futuras pesquisas, o que implica uma ampliação da temática, bem como uma proposição de outros caminhos, outras abordagens para a realização de pesquisas associadas a História da Educação Matemática.

\footnotetext{
${ }^{11}$ A respeito do ensino de desenho, contudo, na escola primária francesa, consultar D'Enfert (2007) nas referências bibliográficas.
} 


\section{Referências}

ARRUDA, Joseane Pinto de. Histórias e práticas de um ensino na escola primária: marcas e movimento da matemática moderna. 2011, 312f. Tese (Doutorado) - Universidade Federal de Santa Catarina, Programa de Pós-Graduação em Educação Científica e Tecnológica, Florianópolis, 2011.

BARREIROS, Manoel Francisco. 0 ensino de geometria nos grupos escolares do Estado de São Paulo (1890 a 1930). 2011, 111f. Dissertação (Mestrado) - Universidade Bandeirante de São Paulo, Programa de Pós-Graduação em Educação Matemática, São Paulo, 2011.

BURKE, Peter. O que é história cultural? Tradução: S. G. de Paula. Rio de Janeiro: Zahar Ed., 2005.

CALKINS, Norman. Allison. Primeiras lições de coisas. Tradução de Rui Barbosa. Rio de Janeiro: Ministério da Educação e Saúde, 1950 (Volume XIII, tomo I das Obras completas de Rui Barbosa).

CARVALHO, Marta Maria Chaga de. Por uma história cultural dos saberes pedagógicos. In: SOUSA, Cyntia Pereira de; CATANI, Denice Barbara (Orgs.). Práticas educativas, culturas escolares, profissão docente. São Paulo: Escrituras, 1998. p. 31-41

D’ENFERT, Renauld. Uma nova forma de ensino de desenho na França no início do século XIX: o desenho linear. Tradução Maria Helena Câmara Bastos. História da Educação, Porto Alegre, v. 11, n. 22, p. 31-60, maio/ago. 2007.

FARIA FILHO, Luciano Mendes de. Escolarização, culturas e práticas escolares no Brasil: elementos teórico-metodológicos de um programa de pesquisa. In: LOPES, Aline et al. Disciplinas e integração curricular: histórias e políticas. Rio de Janeiro: DP\&A, p.13-36, 2002.

FERREIRA, Norma Sandra de Almeida. As pesquisas denominadas "estado da arte". Educação \& Sociedade, Campinas, v. 23, n. 79, p. 257-272, ago. 2002.

FRANÇA, Denise Medina de Almeida. A produção oficial do movimento da matemática moderna para o ensino primário do Estado de São Paulo (1960-1980). 2007, $272 \mathrm{f}$.

Dissertação (Mestrado) - Pontifícia Universidade Católica de São Paulo, Programa de PósGraduação em Educação Matemática, São Paulo, 2007.

FRIZZARINI, Claudia Regina Boen. Do ensino intuitivo para a escola ativa: os saberes geométricos nos programas do curso primário paulista, 1890-1950. 2014, oof. Dissertação (mestrado) - Universidade Federal de São Paulo, Programa de Pós-Graduação em Educação e Saúde na Infância e na Adolescência, São Paulo, 2014.

GASPAR, Jorge Alexandre dos Santos. O Desenho escolar no Rio De Janeiro: uma história de 1890 a 1964. 2014, oof, Dissertação (mestrado) - Universidade Severino Sombra, 
Programa de Pós-Graduação Stricto Sensu do Mestrado Profissional em Educação Matemática, Vassouras, Rio de Janeiro, 2014.

GOMES, Maria Laura Magalhães. Lições de coisas: apontamentos acerca da geometria no manual de Norman Allison Calkins (Brasil, final do século XIX e início do XX). Revista Brasileira de História da Educação, Campinas (SP), v. 11, n. 2(26), p. 53-80, maio/ago. 2011.

KUHN, Thaline Thiesen. Aproximações da geometria e do desenho nos programas de ensino dos grupos escolares catarinenses. 2015, 125f. Dissertação (Mestrado) Universidade Federal de Santa Catarina, Programa de Pós-Graduação em Educação Científica e Tecnológica, Florianópolis, 2015.

MACHADO, Rosilene Beatriz. Entre vida e morte: cenas de um ensino de desenho. 2012, 256f. Dissertação (Mestrado) - Universidade Federal de Santa Catarina, Programa de PósGraduação em Educação Científica e Tecnológica, Florianópolis, 2012.

MENESES, Ricardo Soares de. Uma história da geometria escolar no Brasil: de disciplina a conteúdo de ensino. 2007, 163f. Dissertação (Mestrado) - Pontifícia Universidade Católica de São Paulo, Programa de Pós-Graduação em Educação Matemática, São Paulo, 2007.

OLIVEIRA, Dilma Maria Andrade de. Legislação e educação: O ideário reformista do ensino primário em Sergipe na primeira república - 1889/1930. 2004, 244f. Tese (Doutorado) - Universidade Federal de São Carlos, Programa de Pós-Graduação em Educação, São Carlos, 2004.

PEREIRA, Olinda. A contribuição de estudos brasileiros para o ensino de geometria no ensino primário em Timor-Leste: o caso dos materiais manipulativos. 2012, $159 \mathrm{f}$. Dissertação (Mestrado) - Universidade Estadual de Campinas, Programa de PósGraduação em Educação, Campinas, 2012.

SANTOS, Ivanete Batista dos. Os saberes elementares matemáticos nos grupos escolares: um primeiro balanço (Sergipe, 1911 - 1930). Caminhos da Educação Matemática em Revista, Sergipe, v. 1, n. 1, p.21-47, 2014 a.

SANTOS, Piersandra Simão dos. A escolarização da matemática no Grupo Escolar Lauro Müller (1950 - 1970). 2014, 163f. Dissertação (Mestrado) - Universidade Federal de Santa Catarina, Programa de Pós-Graduação em Educação Científica e Tecnológica, Florianópolis, 2014b.

SILVA, José Claudio Sooma. Teatros da modernidade: representações de cidade e escola primária no Rio de Janeiro e em Buenos Aires nos anos 1920. 2009, 321f. Tese (Doutorado) - Universidade do Estado do Rio de Janeiro, Programa de Pós-Graduação em Educação, Rio de Janeiro, 2009.

SILVA, Maria Célia Leme da. Desenho e Geometria na Escola Primária: um casamento duradouro que termina com separação litigiosa. História da Educação, Porto Alegre, v. 18, n. 42, p. 61-73, jan./abr. 2014. 
SILVA, Maria Célia Leme da.; VALENTE, Wagner Rodrigues. A geometria dos grupos escolares: matemática e pedagogia na produção de um saber escolar. Cadernos de História da Educação, Uberlândia (MG), v. 11, n. 2, jul./dez. 2012.

SILVA, Maria Célia Leme da.; VALENTE, Wagner Rodrigues. Programas de geometria no ensino primário paulista: do império à primeira república. Horizontes, v. 31, n.1, p. 71-79, jan./jun.2013.

SOUZA, Felipe Freitas de. "O desenho é a escrita da indústria": ensino de desenho e educação profissional em Rui Barbosa. 2011, 115 f. Dissertação (Mestrado) - Centro Federal de Educação Tecnológica de Minas Gerais, Programa de Pós-Graduação em Educação Tecnológica, Belo Horizonte, Minas Gerais, 2011.

VALENTE, Wagner Rodrigues. Tempos de Império: a trajetória da geometria como um saber escolar para o curso primário. Revista Brasileira de História da Educação, Campinas, v. 12, n. 3 (30), p. 73-94, set./dez. 2012.

VALENTE, Wagner Rodrigues. A matemática na escola: um tema para a História da Educação. In: MOREIRA, D.; MATOS, J. M. (Org). História do ensino da matemática em Portugal. Lisboa: Sociedade Portuguesa de Ciências da Educação, 2005, p. 21-32.

VIDAL, Diana Gonçalves. Culturas escolares: estudo sobre práticas de leitura e escrita na escola pública primária. Campinas - SP: AA, 2005.

Recebido em: 10/02/2015

Aprovado em: 25/03/2015

Universidade do Estado de Santa Catarina - UDESC Programa de Pós-Graduação em Educação - PPGE Revista Linhas Volume 17 - Número 33 - Ano 2016 revistalinhas@gmail.com 